\title{
The energy supply for mountain settlements in Tajikistan based on renewable energy sources
}

\author{
D. Schulz ${ }^{2}$, A. D. Ahrorova ${ }^{1}$, M. K. Halimjanova ${ }^{1} \&$ K. H. Kholov ${ }^{1}$ \\ ${ }^{1}$ Tajik Technical University, Tajikistan \\ ${ }^{2}$ Helmut-Schmidt-University/University of the Federal Armed Forces, \\ Hamburg, Germany
}

\begin{abstract}
This article investigates the electrification of mountain villages in Tajikistan through the use of combined renewable energy sources. The decentralized electricity supply to mountain areas in particular can mitigate serious problems related to the population's limited access to energy in winter. Firstly, a view to ensuring the reliability of the energy supply to the zones is carried out. Secondly, recommendations on the use of small hybrid hydropower stations in inaccessible mountain areas of the republic are given.

Keywords: energy security, small hybrid hydropower stations, transmission lines, decentralized electricity zone, photovoltaic (PV) station.

\section{Introduction}

The market transformation of the Tajik economy's transition to new forms of state authority and management and deep social transformation has caused various risks and threats to people's lives. Currently, a fundamental problem for national energy security could be solved by the sustainable development of the energy sector. As in any other country, the energy security in Tajikistan is an important issue and has a high impact on the living standards of people. Energy security is largely determined by access to the energy supply through reliable resources.
\end{abstract}

\section{Problem description}

Because of the limited access to alternative energy sources the demand for electricity strongly increases during winter time. This situation is worsened by the weak diversification of generation sources of the national energy system, 
which has in its structure a large amount of conventional hydroelectric power. The maximum capacity of hydroelectric power production is needed in full during the autumn and winter. There is a pent-up demand for electricity with an average amount of $4.3 \mathrm{TWh}$ in the republic. For this reason every year from October to March restrictions (limits) to the electrical power (energy) supply exist. For example, in 2009-2010 the electricity supply was limited to 7 to 12 hours a day. Limitation generally affected all consumers, with the exception of certain cities (Dushanbe, Khujand) and enterprises with strategic importance for the country's economy, such as an aluminum plant. The unsatisfied electric energy demand in the autumn-winter period is illustrated in Fig.1.

In Tajikistan, the main natural energy resources are hydro and solar energy. In the republic an amount of $64 \mathrm{~km}^{3}$ of water per year flows through the especially small rivers, which are almost uniformly covering the entire country. Tajikistan holds the 8th rank in the world for its total value of hydropower resources and the first and second, respectively, for specific hydropower reserve per capita and per unit of land area. The potential for hydropower is estimated to over $527 \mathrm{TWh}$ per year, and currently used by only $3 \%$. This creates favorable conditions for the development of hydropower in the country. Figure 2 shows a map of the state and prospects of the development of hydropower and renewable energy sources in the Republic of Tajikistan.

As it can be seen in the map (Figure 2) and in the diagram (Figure 1), Tajikistan has an energy deficit in the autumn-winter period despite the significant potential for renewable energy. At this point of time about 26 thousand people in the republic still live in areas that are not electrified.

These zones are shown on the map in Figure 2 in black circles. Electric power supply of remote mountain settlements from the centralized grid is a complex and relatively expensive solution due to the low population density and

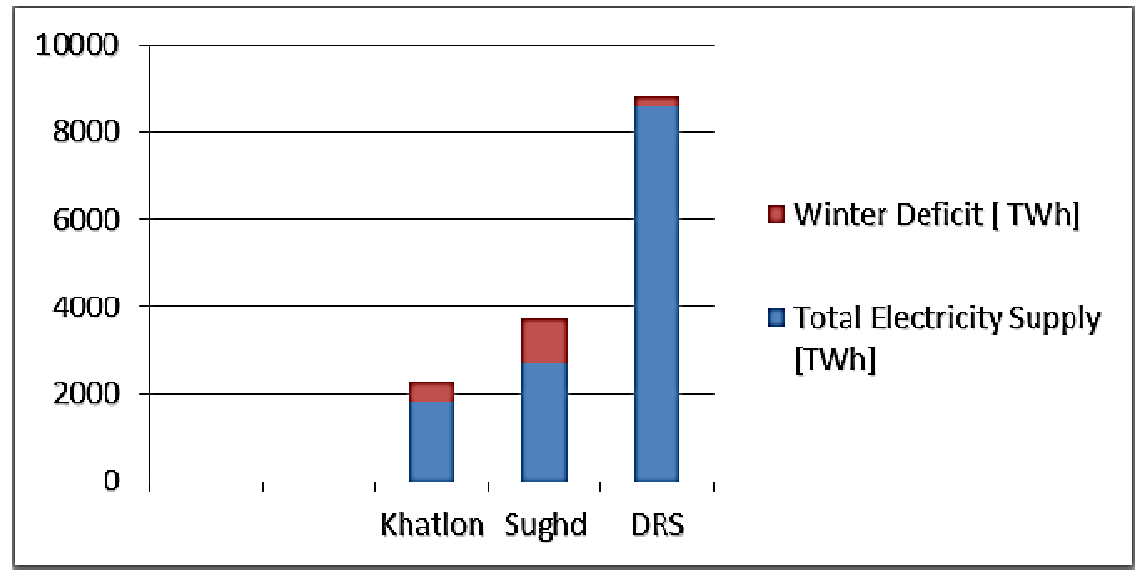

Figure 1: Production and energy deficit in the autumn-winter period. DRS - Districts of Republican Subordination. 
mountainous terrain. It should be noted that the use of renewable energy might be the key in ensuring sustainable development of mountain settlements of our country, having a positive impact on public health, family budgets and ecology villages. A reliable power supply to mountainous regions in modern conditions brings obligatory account to two important points concerning the quality of life:

- $\quad$ socio-economic status of the population increases with access to energy;

- energy is a good which is always in demand; it is a driver for development.

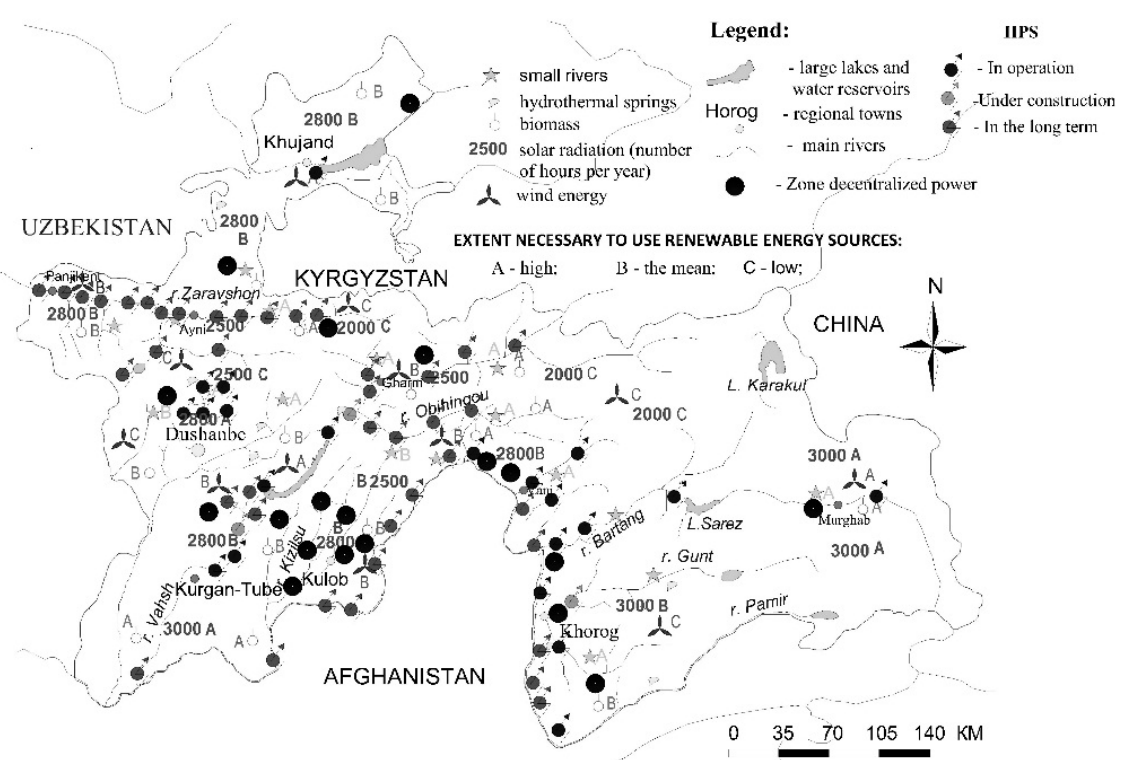

Figure 2: Status and prospects of development of hydropower in Tajikistan including potential for alternative energy sources.

\section{Proposed solution}

The calculations show that the use of small hydropower plants as a source of electric power in mountain settlements relating to zones of decentralized power supply are today the most economical solution of energy problems in Tajikistan. Connecting zones of decentralized power supply to the network using the transmission lines does not give the expected effectiveness for the reason that the country's energy system has no free capacity in the winter. In addition, due to remoteness of decentralized zones and low population density their power supply is only possible with high technical and economical efforts. The length of medium voltage distribution lines $6-10 \mathrm{kV}$ would be $20-40 \mathrm{~km}$. Such lines in extreme climatic conditions are often damaged, especially in the winter. In addition to this, long medium voltage lines cause high transmission losses. As 
a result, even close to the district center of located settlements, the duration of interruption of power supply ranges from 10 to 20 days. As a result, there is a low quality of electricity supply. The voltage on the network of regional centers of closely spaced villages is $160-180 \mathrm{~V}$, and in remote settlements, it is reduced to 140-160 V. All this results in increased wear of current collectors, complicates the use of modern household appliances and has a negative impact on the socio-economic development of the region. The population numbers of the country regions without access to electricity are presented in Figure 3.

Characteristics of technical and economic parameters of transmission line constructions in Tajikistan are given in Table 1 [2]. Analysis of calculation results shows that in the mountainous, inaccessible locations with a low density people construction of a small hydropower plant has the lowest cost compared to the construction of transmission lines from existing sources of medium voltage and high voltage power.

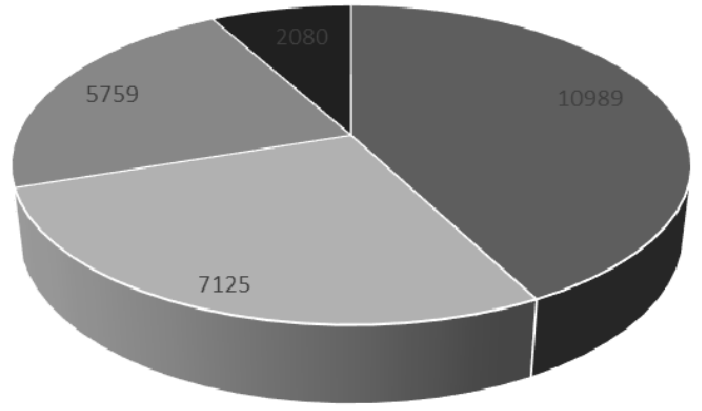

- Hatlon = Badahshon = Sughd - Districts of Republican Subordination

Figure 3: $\quad$ Number of people without granted access to a centralized electric power supply to the sectional territorial divisions of Tajikistan [3].

Table 1: Characteristics of transmission lines.

\begin{tabular}{|c|c|c|c|c|}
\hline $\begin{array}{l}V \text { in } \\
\mathrm{kV}\end{array}$ & $\begin{array}{c}\text { The type of } \\
\text { bearings }\end{array}$ & $\begin{array}{c}\text { The } \\
\text { maximum } \\
\text { transmitted } \\
\text { power in } \mathrm{kW}\end{array}$ & $\begin{array}{l}\text { Technically } \\
\text { feasible } \\
\text { electricity } \\
\text { transmission } \\
\text { distance in } \mathrm{km}\end{array}$ & $\begin{array}{c}\text { The cost of } \\
\text { building the } \\
\text { transmission line } \\
\text { in } \\
\text { thousand } \$ / \mathbf{k m} \text {. }\end{array}$ \\
\hline 0,4 & Wooden & 100 & 0.25 & 12.4 \\
\hline 10 & Ferroconcrete & 3000 & 15 & 14.0 \\
\hline 35 & Metal & 10000 & 50 & 37.3 \\
\hline 35 & $\begin{array}{l}\text { Ferroconcrete + } \\
\text { Metal }\end{array}$ & 10000 & 50 & 37.3 \\
\hline 110 & $\begin{array}{l}\text { Ferroconcrete + } \\
\text { Metal }\end{array}$ & 50000 & 150 & 57.3 \\
\hline 220 & $\begin{array}{l}\text { Ferroconcrete + } \\
\text { Metal }\end{array}$ & 20000 & 250 & 71.4 \\
\hline 500 & Metal & 50000 & 700 & 160 \\
\hline
\end{tabular}


The cost of building small hydroelectric power depends on its type, capacity, construction area, etc. In domestic practice when designing small hydropower, a specific capital investment is usually taken equal to $1000 \mathrm{US} \$ / \mathrm{kW}$. Executed analysis of actual cost of constructed small hydropower stations in Tajikistan (Figure 4) shows the substantial deviation from the specific capital investments used in design practice. Thus, the cost of $1 \mathrm{~kW}$ of installed capacity of small hydropower "Pitavkul" is 2050 US \$.

Also the positive aspects of construction of small hydropower plants in the mountainous regions of our country should be mentioned. The main advantages of a small hydropower plant construction are:

- Localized supply electricity;

- Small branching network of $10 \mathrm{kV}$ and $0.4 \mathrm{kV}$;

- Reduced energy losses due to the proximity of small hydropower plants to consumers;

- Fast construction time;

- Social effects, manifested in raising living standards, creating new jobs.

Despite the positive effects of the construction of small hydropower stations, its real power capacities and energy reliability should be considered in order to avoid wrong expectations from its construction. Also very important is the organization of the monitoring program for the development of small hydropower in the country. Like any isolated, localized source of energy, small hydropower depends on the flow rate of water in the watercourse, and therefore, it is characterized by a lack of reliability of power supply. The solution is to create a combined energy systems, including wind generator, mini-boiler (biofuel) and photovoltaic installation.

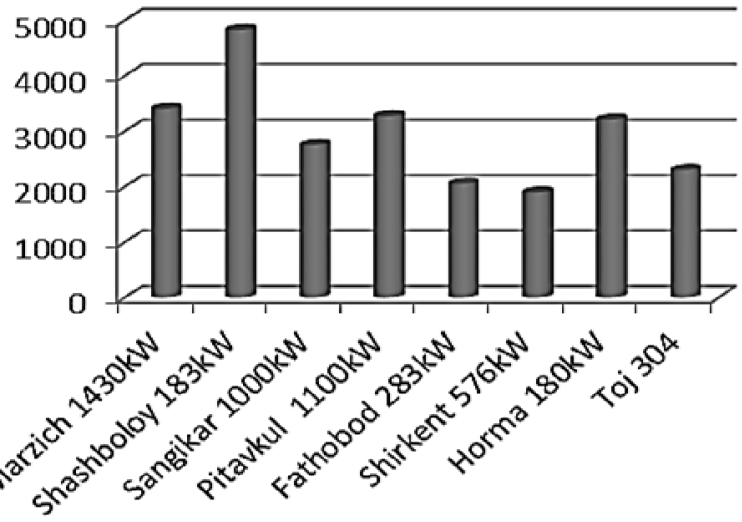

cost of $1 \mathrm{~kW}$ of power

Figure 4: $\quad$ Cost of $1 \mathrm{~kW}$ of installed capacity for SHP. 


\section{Practical example and results of investigation}

This section presents the results of research on the use of solar and hydropower and substantiates recommendations on the best mode of the hybrid stations in populated mountain regions of Tajikistan. The example of a hybrid small hydro power plant (HPP) and photovoltaic power plant (PV), as an existing small hydro power plant "Artuch" in the Pendzhikent area in the Republic of Tajikistan, was investigated. It was put into operation in 2006.

The small hydro power plant "Artuch" consists of one hydro generator with a nominal power of $500 \mathrm{~kW}$, the output voltage of $0.4 \mathrm{kV}$ is increased for transmission by a step-up transformer of the type TM-630/0.4/10 kV. This hydroelectric power station type is a derivation of the type without a reservoir, which depends directly on the flow of water. As a result of some special assumptions in the design stage of a small HPP "Artuch" cannot deliver the full installed capacity and therefore not fully meet the corresponding consumer demand. For higher energy security of the region and improved fulfilling of the consumer demand, a combination of the HPP with a solar PV is proposed.

Calculations of transmission lines and losses were performed at the HelmutSchmidt-University/University of the Federal Armed Forces Hamburg, Germany, using the program DIgSILENT PowerFactory 14.0. Calculations showed that to meet the consumer demand in this locality solar panels with an output power of $135 \mathrm{~kW}$ have to be installed. This power will be delivered under the condition that a sunny day would last at least 7 hours, which is typical for this region. Under consideration of the necessary electricity supply power, an area of $132 \mathrm{~m}^{2}$ is occupied by the solar panels. The proposed scheme is shown in Figure 5.

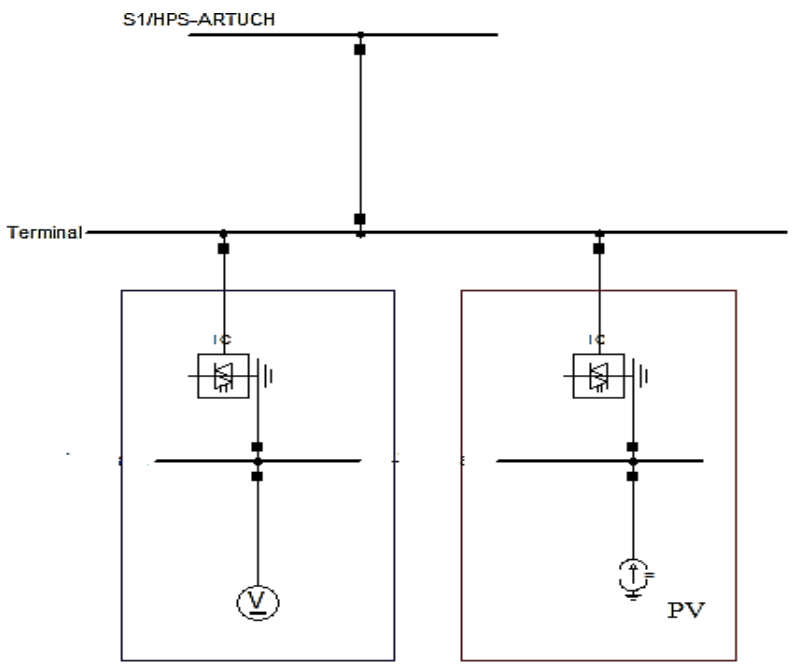

Figure 5: $\quad$ Scheme of a hybrid power plant. 
The cost of electricity generated by the solar $1 \mathrm{~kW}$ station would be 0.12 US \$, the electricity tariff in Tajikistan for $1 \mathrm{~kW}$ is 0.00231 US \$.

Generating electricity using solar panels, the existing deficit of active power can be covered, if the hydro-generator delivers a maximum power of $180 \mathrm{~kW}$, which is a realistic value in the summer. The power output of a hybrid installation and annual load curve under consideration of the village are shown in Figure 6 .

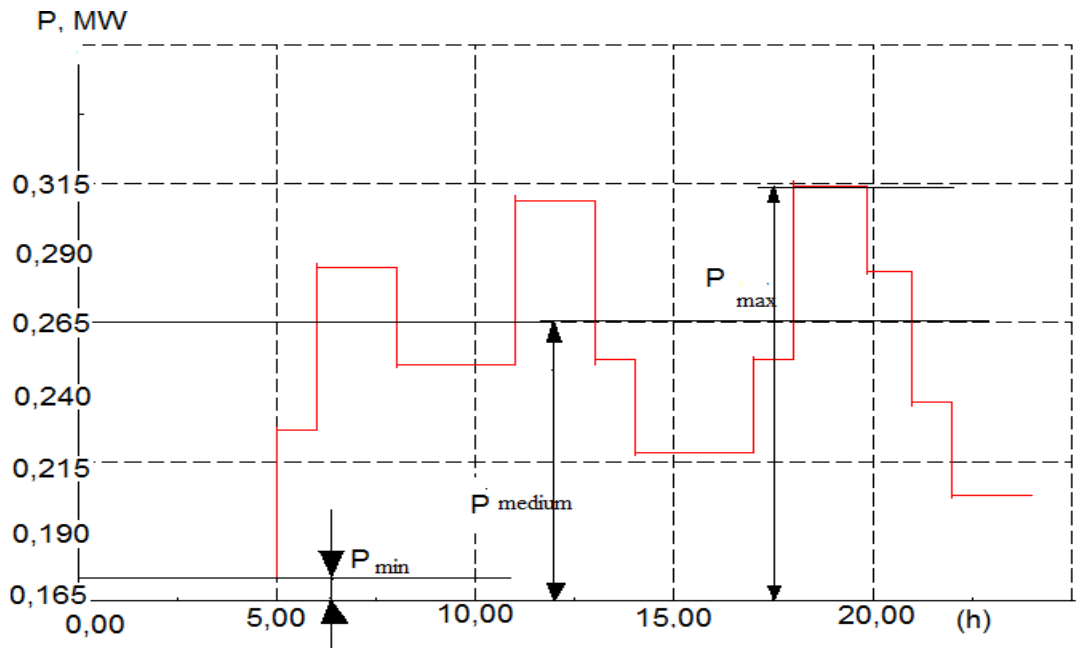

Figure 6: Daily load schedule of hybrid SHP "Artuch".

\section{Conclusion}

For the Republic of Tajikistan, where deficiency of energy is great, it is necessary to have an additional alternative energy source. It is necessary to introduce and develop hybrid power stations with high reliability and efficiency of the electric power. Such hybrid power stations must be a suitable application under mountainous conditions. This paper summarizes the investigations and results of the first steps towards a more reliable energy supply to mountain villages with hydro and photovoltaic power supply in Tajikistan. The use of hybrid power installation will increase the energy security of the village. Further development of such solutions will contribute to the national energy security and improvement of the standards of living in Tajikistan.

\section{References}

[1] Ahrorova A., Amindžanov R. M., Dronkin K. Energy of Tajikistan: recent trends and prospects for sustainable development. Dushanbe: Publishing LLC RIA status, 2005. p. 225. 
978 Energy Production and Management in the 21st Century, Vol. 2

[2] Ibrahim A., Leonidov N. V., Petrov G. N. Industrial use of small hydropower in Tajikistan//Mountain magazine. 2004. Special Edition, pp. $40-43$.

[3] Compiled from materials of the Ministry of Energy and Industry of the Republic of Tajikistan. 